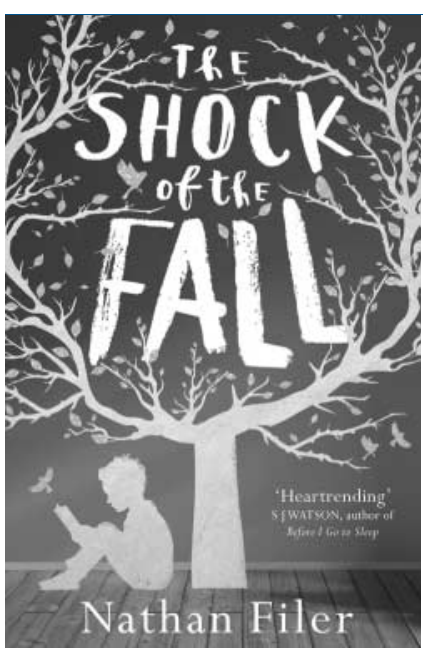

\section{The Shock of the Fall}

By Nathan Filer.

Harper Collins/The Borough Press. 2014.

f7.99 (pb). 320 pp.

ISBN: 9780007491452

I will not pretend not to have felt a good bit jealous when I heard about The Shock of the Fall; first novel and Costa Book Award winner, by psychiatric nurse Nathan Filer. Where are all the psychiatrists when it comes to fiction writing? Well, they are certainly not to be found in this story. If, as a psychiatrist, you are hoping to find yourself portrayed for better or worse within the 300 pages of this tale of mental illness, you will be, frankly, disappointed. It is much worse than that. Psychiatrists are mentioned less than a handful of times throughout. On the face of it this may seem surprising, given that Matthew Homes, the narrator and central character, spends a significant part of the novel in an acute psychiatric unit, a little time on a high-dependency unit and is subsequently discharged on a community treatment order. But this is Matthew's story; the story of a young man struggling with a mental illness and looking back on the emotional fallout since the death of his brother in childhood.

Matthew's experiences of being a psychiatric patient both in and out of hospital are recounted with blush-inducing perceptiveness of what it must be like for patients caught up in modern-day mental health services and will undoubtedly ring true with any psychiatric professional, patient or carer. It is not a comfortable read.

The story begins at a holiday park a couple of days before Matthew's brother, Simon, dies in circumstances which are kept tantalisingly oblique until the near end. Near end that is, not the bitter end which you may be forgiven for anticipating as you progress through the book. Simon has Down's syndrome and intellectual disability and dies; Matthew has grief, guilt, drugs and schizophrenia; there is more than a hint that their mother suffers from recurrent depression and Munchausen syndrome by proxy; and Matthew's dope-smoking best friend is chained as a carer for a severely disabled parent. At first glance it reads more like a diagnostic manual which is not really the stuff of comedy and yet there are genuine laugh-out-loud moments which come as a more-than-welcome respite from this otherwise quietly disturbing novel.

Nothing seems to escape Filer's microscopic gaze in his effort to paint a searingly accurate canvas of the world inhabited by patients, but it is the external world within the confines of the hospital, rather than the internal world of Matthew's mental illness, where the observations of staff and his interactions with them are so well crafted with a brutal insight that makes you cringe and laugh in equal measure. The risk assessment form, in particular, is a masterful parody of justification, and I would challenge anyone having read this novel to ever complete another in the same way again. I have already said that psychiatrists make a very brief showing and also that it is a very real and true account of the current mental health services. The fact is that from Matthew's vantage point the psychiatrist is a very peripheral character with whom he has no interaction or relationship outside of the brief and heavily populated ward round. Apart from the very talented storytelling Nathan Filer has produced a fine description of psychiatry under New Ways of Working.

Some people read novels and say 'I didn't want it to end'. I wanted this book to end. If I am honest, I probably wanted it to end at the top of the cliff on page 247. It left me feeling sad. Sad for the patients, carers, nurses, support workers, but mostly sad for psychiatry.

Naomi Mehta Northumberland, Tyne and Wear NHS Trust, Northgate Hospital, Morpeth NE61 3BP, UK. Email: naomi.mehta@ntw.nhs.uk

doi: 10.1192/bjp.bp.114.150821

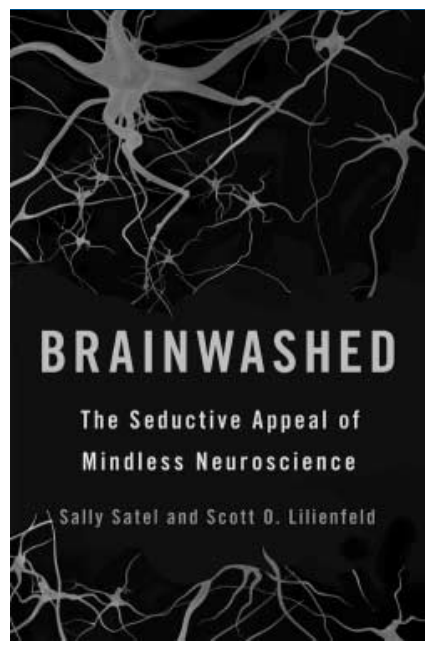

\section{Brainwashed:}

The Seductive Appeal of Mindless Neuroscience

By Sally Satel \& Scott O. Lilienfeld. Basic Books. 2013.

US\$26.99 (hb). $154 \mathrm{pp}$.

ISBN: 9780465018772

With this impressive book, Satel \& Lilienfeld (practising clinicians in psychiatry and psychology respectively) have achieved a timely and balanced work on the limits of contemporary neuroscience. Brainwashed is an exposé of 'mindless neuroscience: the oversimplification, interpretive license, and premature application of brain science in the legal, commercial, clinical and philosophical domains', and a damning critique of our now dominant assumption that a biological/neural explanation is the best way to understand human behaviour.

The authors acknowledge neuroscience as a hugely important and influential field but emphasise its fledgling status. They focus particularly on the fMRI, the hallmark tool of neuroscience, and misapplied neuroscience, outlining the dangers of stretching paradigms beyond their appropriate use. The potential results are not only 'neuroredundancy' (fMRIs telling us things we already know about the world and contributing little or nothing in terms of useful data or knowledge) but also real societal harm.

Brainwashed is a cautionary tale on the dangers of reductionism and the central question running through the book is whether we can ever understand the psychological through the neurological. This is, of course, nothing new, it is one of our oldest philosophical debates - the mind/body (brain) divide and the 